\title{
Editorial
}

\section{Could wildlife survive a nuclear winter?}

More than 100 scientists attending the Conference on the World after Nuclear War were unanimous in concluding that a large-scale nuclear war would gravely and permanently damage the ecosystems of the world. The findings presented at the conference, which took place between 31 October and 1 November 1983 in Washington DC, detailed effects far worse than any which have been predicted previously.

Two of the conference's key papers have since been published in Science*. One, entitled Nuclear Winter: Global Consequences of Multiple Nuclear Explosions, describes the potential global atmospheric and climatic consequences of nuclear wars of magnitudes ranging from 100 to 10,000 megatons. All the nuclear exchanges within this range would, the authors predict, create a pall of smoke and dust that would quickly encircle the earth. After a 10,000megaton exchange they calculate that light would be reduced to approximately one per cent of normal and that land surface temperatures in continental interiors could fall to $-40^{\circ} \mathrm{C}$. It would take at least one year for light and temperature values to recover to normal. But even a 'smallscale' attack, using bombs totalling 100 megatons (and equal to only 0.8 per cent of the combined strategic arsenals of the world) could, if the bombs were dropped on major urban centres, where the resulting fires would be enormous, create sufficient smoke to obscure the sun for weeks and to depress surface temperatures to well below freezing (from -15 to $-25^{\circ} \mathrm{C}$ ) for many months.

The effects would not be confined to the northem hemisphere-where it is assumed that a war is most likely to take place. The large differences in temperature gradients, caused by the absorption of sunlight by dust and smoke clouds, could disturb global circulation patterns and result in the transport of nucler debris to the southern hemisphere.

In the paper, Long-Term Biological Consequences of Nuclear War*, the 20 authors translate these climatic changes into their significance for the living organisms of the earth. They take the worst of the range of scenarios studied, the Editorial 10,000-megaton war. In this case, immediately after the explosion an estimated 30 per cent of the northern hemisphere mid-latitude areas would receive a dose of radiation comparable to or more than the acute mean lethal dose for healthy adult humans. In the weeks after, fallout would carry radiation to 50 per cent of the northern midlatitudes and months of darkness and sub-freezing temperatures would follow. Photosynthesis would cease, cutting off the food base of ecosystems. Animals would die from starvation or from exposure. Thick ice would cover bodies of freshwater. In the tropics temperatures and light levels would also fall, sufficiently to decimate many tropical species. The year that follows could witness the extinction of many tropical species, the collapse of marine ecosystems that depend on phytoplankton, the loss of a huge number of freshwater species and terrestrial vertebrates. After the dust and smoke settle, survivors would suffer damaging doses of ultraviolet radiation from the sun through destruction of the ozone layer.

Although this picture results from considering the effects of a large-scale nuclear exchange, it is by no means the worst that could be imagined given the present world nuclear arsenal. And a war of a more limited extent would have qualitatively similar effects. The possibility exists that darkened skies and low temperatures could envelop the entire planet and the majority of the world's species could become extinct. In that event, the authors conclude, 'the possibility of the extinction of Homo sapiens cannot be excluded'.

With such findings before us and with such terrifying prospects ahead, it seems no longer possible that biologists or conservationists anywhere in the world can avoid becoming involved in the nuclear debate.

*The two papers referred to here are : Turco, R.P., Toon, O.B., Ackerman, T., Pollack, T.B. and Sagan, C. 1983 Science, 222, 1283, and Ehrlich, Paul R., Harte, John, Harwell, Mark A., Raven, Peter H., Sagan, Carl, Woodwell, George M., Berry, Joseph, Ayensu, Edward S., Ehrlich, Anne H., Eisner, Thomas, Gould, Stephen J., Grover, Herbert D. Herrera, Rafael, May, Robert M., Mayr, Ernst, Mckay, Christopher P., Mooney, Harold A., Myers, Norman, Pimentel, David and Teal, John M. 1983. Science, 222, 1293. 